\title{
A state-of-art survey on TQM applications using MCDM techniques
}

\author{
Yasaman Mohammadshahi*
}

Department of Industrial Engineering, Faculty of Engineering, University of Tehran, Tehran, Iran

\section{H R O N I C LE ABSTRACT}

Article history:

Received October 2, 2012

Received in Revised Format

March 12, 2013

Accepted March 18, 2013

Available online

March 202013

Keywords:

Multi criteria decision making

$T Q M$

QFD

Fuzzy TOPSIS

\begin{abstract}
In today's competitive economy, quality plays an essential role for the success business units and there are considerable efforts made to control and to improve quality characteristics in order to satisfy customers' requirements. However, improving quality is normally involved with various criteria and we need to use Multi Criteria Decision Making (MCDM) to handle such cases. In this state-of the-art literature survey, 45 articles focused on solving quality problems by MCDM methods are investigated. These articles were published between 1994 and 2013.Seven areas were selected for categorization: (1) AHP, Fuzzy AHP, ANP and Fuzzy ANP, (2) DEMATEL and Fuzzy DEMATEL, (3) GRA, (4) Vikor and Fuzzy Vikor, (5) TOPSIS, Fuzzy TOPSIS and combination of TOPSIS and AHP, (6) Fuzzy and (7) Less frequent and hybrid procedures. According to our survey, Fuzzy based methods were the most popular technique with about $40 \%$ usage among procedures. Also AHP and ANP were almost $20 \%$ of functional methods. This survey ends with giving recommendation for future researches.
\end{abstract}

\section{Introduction}

Multi Criteria Decision Making (MCDM) is one of the most important branches of operation research whose aim is to design mathematical and computational tools to select the best alternative among several ones with respect to specific criteria by a single decision maker or by a group. This field consists of two main categories: Multi Attribute Decision Making (MADM) and Multi Objective Decision Making (MODM). Effective methods were developed for dealing with problems in each of these two branches. This paper provides a state-of the-art literature survey on MCDM applications in solving quality problems. In order to gain this goal, 45 articles focused on this specific issue were surveyed. In the rest of the paper, procedures of some MCDM methods are described. Then, frame work for literature review is explained. In section 4, all the investigated articles are studied in detail. In follows, section 5 demonstrates frequency of each metods and section 6 presents concluding remarks.

* Corresponding author. Tel: +989124784598

E-mail addresses: mohammadshahi@ut.ac.ir (Y. Mohammadshahi)

(C) 2013 Growing Science Ltd. All rights reserved.

doi: $10.5267 /$ j.dsl.2013.03.004 


\section{Most practical MCDM procedures}

\subsection{Analytic Hierarchy Process (AHP)}

AHP was found by Thomas L. Saaty in 1980 and It is a popular and widely used method for multi criteria decision making, which allows the use of qualitative as well as quantitative criteria in evaluation of alternatives.

\subsection{Analytic Network Process (ANP)}

ANP was proposed by Thomas L. Saaty in 1996, which is a more comprehensive decision making technique is an extension of AHP where it tries to overcome the problem of dependence and feedback among criteria.

\subsection{Decision Making Trial and Evaluation Laboratory (DEMATEL)}

DEMATEL was first stated in the Geneva Research Center of the Battelle Memorial Institute (Gabus \& Fontela 1973 ; Fontela \& Gabus 1976). This technique portrays the relationships with matrices or diagraphs visualizing a contextual relation between the elements of the system and represents the strength of influence by a numeral.

\subsection{Grey Relational Analysis (GRA)}

GRA was described by Deng (1982) and it needs grey relational degree calculated based on changing alternatives into comparable sequences and defining an ideal target sequence.

\subsection{Vikor}

For solving decision making problems with conflicting and non-commensurable criteria, Vikor method (2004) was developed by Opricovic and its goal is to find the closest solution to ideal.

\subsection{Technique for Order of Preferences by Similarity to Ideal Solution (TOPSIS)}

Hwang and Yoon developed TOPSIS in 1981 and it chooses alternatives having the shortest distance from positive ideal solution and the farthest distance from the negative ideal solution.

\subsection{Fuzzy}

Zadeh (1965) is believed to be the first who introduced the concept of Fuzzy logic. This concept emphasizes on approximate values rather than fixed and exact ones and several applications were generated by using fuzzy logic in recent years.

\subsection{Goal Programming}

Goal programming is an MODM tool, which was first employed by Charnes et al. (1955). It can be thought as an extension of linear Programming to solve problems containing multiple and usually conflicting objects.

\subsection{Elimination and Choice Expressing Reality (ELECTRE)}

ELECTRE was expressed by Roy (1991) and his colleagues at SEMA Consultancy Company and then evolved into ELECTRE I, ELECTRE II, ELECTRE III, ELECTRE IV, ELECTRE IS and ELECTRE TRI (ELECTRE Tree). This method consists of two sets of parameters: The importance coefficient and the veto thresholds. 


\subsection{Data Envelopment Analysis (DEA)}

DEA is focused on measuring the efficiency of multiple decision making units in the situation of having multi inputs and outputs. Charnes et al. (1978) are believed to be the first who introduced the idea of DEA for performance measurement and they extended theoretical framwork, more comprehensively (Charnes et al., 1994). There are literally various applications of DEA method in different industries (Lin et al., 2009; Che et al., 2010). Thoraneenitiyan and Avkiran (2009), for instance, measured the impact of restructuring and country-specific factors on the efficiency of postcrisis East Asian banking systems

\section{Framework for literature review}

This literature review was performed to shed light into MCDM methods, which are capable of using in quality problems. The most important library databases include Science direct, Scopus, Elsevier, Springer, IEExplore and Emerald were searched. Text books and theses were not considered in this review.

\section{Application of each MCDM methods in quality problems}

\subsection{AHP, Fuzzy AHP, ANP and Fuzzy ANP}

As mentioned earlier, ANP can be considered as an extension of AHP and these two techniques are presented in the same category.

Ahire and Rana (1995) proposed an MCDM model using AHP to identify and to select key pilot of Total Quality Management (TQM) projects and worked on developing it. This model helps organizations prioritize and enhance the returns from TQM efforts applied to a hospital environment.

Bhattacharya et al. (2010) explained a concurrent engineering approach unifying AHP with Quality Function Deployment (QFD) in combination with Cost Factor Measure (CFM) to rank and to select candidate suppliers under multiple and conflicting criteria environment. Oh et al. (2006) evaluated the Quality of Radio Frequency Identification (RFID) middle ware in ubiquitous computing systems by using AHP. The proposed evaluation method is useful for developers implementing RFID middle ware in areas such as distribution and logistics to choose RFID middle ware suitable for their environment.

Chang et al. (2008) presented a new approach to select unstable slicing machine to control wafer slicing quality based on Fuzzy AHP algorithm. Bilsel et al. (2006) assessed the performance of the websites of Turkish hospitals on the basis of a conceptual framework consisting of seven major eservice quality dimensions. AHP method and fuzzy numbers were exercised correspondingly in weighting and evaluating process.

Raut et al. (2011) suggested a model including Quality Function Deployment (QFD), Fuzzy technique and AHP in an attempt to examine the improvement of Indian auto mobile industry. A developing QFD-fuzzy model as a foundation for comparing the reliability of results of the MCDM techniques was stated. Eventually, the necessities to improve Indian auto mobiles on various fields were ranked.

Büyüközkan et al. (2011) examined the concept and factors of service quality. For analyzing the proposed service quality framework, Fuzzy AHP was introduced. This methodology was conducted in health care sector in Turkey. Hsieh et al. (2008) investigated on ANP to find the relative weight and to emphasize on interrelationships among the criteria for evaluating the hot spring hotels service quality in Taiwan.

Fatchurrohman et al. (2012) described a technique combining Concurrent Network (CE-ANP), Quality Function Deployment (QFD) and AHP. Selection of wing spar material in the field of 
aerospace was offered as a case study. Tseng (2009a) employed DEMATEL and ANP, Liou and Tzeng (2007) utilized GRA and ANP, also Cheng (2012) used Fuzzy ANP and Fuzzy Vikor. These articles are respectively reviewed in sections 4.2, 4.3 and 4.4.

\subsection{DEMATEL and FUzzy DEMATEL}

Wang et al. (2011) explained a method impressed by DEMATEL and Fuzzy set theory to assess customer perceptions on airline service quality under uncertainty. Effective questionnaire data provided by 145 customers from China Airlines and EVA Airways were collected. Testing the cause effect relationships and correlations among the various evaluation criteria became possible by the means of DEMATEL.

Cebi (2012) proposed a method based on Fuzzy set theory, DEMATEL and generalized choquet integral techniques in order to evaluate the design quality of online shopping websites. Quality of the most used shopping websites in Turkey was assessed by this approach. Tseng et al. (2012) focused on integrated model of hot spring service quality perceptions under uncertainty. Fuzzy set theory helped evaluate the subjective and objective functions. Evaluation of the model for strategic goals was done by extension of DEMATEL. Tseng (2009a) suggested a procedures derived from ANP and DEMATEL for helping the expert group evaluating the different municipal solid waste management (MSW) solutions in Metro Manila.

Tseng (2009b) overcame the objective of the study by a combined grey-fuzzy DEMATEL method. This study presented a perception approach to deal with real estate agent service quality expectation ranking in uncertainty. Triangular fuzzy numbers described weights of criteria and alternatives. DEMATEL was employed to resolve interdependency relationships among the criteria.

Wang and Chen (2012) stated a method, which contains Fuzzy MCDM rooted in Quality Function Deployment (QFD) integrating Fuzzy Delphi and Fuzzy DEMATEL with linear integer programming. This procedure was proposed as a means of collaborative product design and optimal selection of module mix. Moreover, a real case study on developing various types of sport and water digital cameras was provided.

\subsection{GRA}

Kuo et al. (2007) strongly emphasized on building the criteria of service quality in a real-life environment, which contains both dependent, independent, interdependent criteria and vague or fuzzy data. A relationship analysis method combining fuzzy sets and GRA was explained. In empirical, selection of criteria was applied for bus industries in Taiwan to prove the effectiveness of this approach.

Kodou et al. (2012) commented on the procedure combining TOPSIS and GRA for improving Airline service quality. Liou and Tzeng (2007) developed a non-additive model for evaluating and improving the service quality of Airlines factor analysis to extract some independent common-factors and fuzzy integral used to integrate the performance ratings of interdependent attributes in each common-factor. To determine the relative weight linking each independent common-factor ANP was exercised. At last, airline service quality was found by Simple Additive Weighting (SAW) and GRA.

Liou et al. (2011a) investigated on improving service quality among domestic airlines in Taiwan by means of modified GRA. A new ranking index to measure the Airline's competitiveness in terms of service quality was also developed. Managerial improvements were performed to achieve the aspired level of customer satisfaction were suggested. Kuo (2011a), Kuo and Liang (2011b) combined GRA and Vikor in their procedures; These articles are brought in 4.4. 


\subsection{Vikor and Fuzzy Vikor}

Chou and Cheng (2012) merged Fuzzy ANP and Fuzzy Vikor to assess web site quality of the topfour CPA firms and gave some suggestions for boosting web site design and content. The results of this study helps CPAs know their status among their rivals and enhance their situation. Liou et al. (2011b) described a modified Vikor method for improving service quality among domestic airlines in Taiwan. This model demonstrated the gaps between alternatives and aspired levels in practice. Managerial implications were also provided for different carriers to achieve aspired levels.

Kuo (2011a) evaluated service quality of Chinese cross-strait passenger Airlines via customer surveys by combining Vikor, GRA and interval-valued fuzzy sets. According to this method, decision makers are enabled to measure gaps between options and aspired level. Advantages and disadvantages of an Airline in specific area of passenger service also can be understood. Kuo and Liang (2011b) presented a new MCDM method by Vikor and GRA in order to solve evaluation of service quality problems. Evaluating service quality of seven major Northeast-Asian international airports was carried out to clarify an application of the proposed model.

\subsection{TOPSIS, Fuzzy TOPSIS, combination of TOPSIS and AHP}

Tsaur et al. (2002) focused on Fuzzy set theory to assess the service quality of Airline. Fuzzy set theory was used for measuring the performance. Weighting criteria and ranking were performed by AHP and TOPSIS. By this procedure, changing intangible attributes in evaluating the service into tangible ones became feasible. Büyüközkan and Çifçi (2012a) combined Fuzzy AHP and fuzzy technique for ordering performance by TOPSIS. Electronic service quality used in healthcare industry was analyzed by this procedure.

Saremi et al. (2009) stated a systematic decision making process for selecting external consultant based on TOPSIS method in fuzzy environment. Hessami et al. (2012) obtained the most important factors and sub factors of successful implementation of ISO-14001 based environmental management system (EMS) by the means of TOPSIS. Critical sub factors of implementation of ISO 14001 in cement industry in Iran were found by this method.

Shahin and Poormostafa (2011) employed an integrated technique of simulation, Fuzzy AHP and Quality Function Deployment (QFD) for improving and optimizing facility layout design. The weights of qualitative measures for layout alternatives were determined by AHP. Weights of criteria and importance of alternatives were proposed by QFD. TOPSIS were selected for ranking the alternatives and identifying the best one.

Bueyuekoezkan and Ruan (2007) suggested a framework of web site quality evaluation for measuring the performance of government web sites. Different websites were prioritized concerning to their overall performance by using Fuzzy AHP and Fuzzy TOPSIS. Majumdar et al. (2005) determined quality value of cotton fibre by exercising hybrid AHP-TOPSIS method. Cotton fibre properties were considered and their relative weight attained by a typical pair-wise comparison. Cotton fibres were ranked according to the best and worst possible alternatives.

Zhu (2008) modeled web quality by a using web quality model, web QM. Fuzzy TOPSIS helped evaluate and screen web sources for advanced web application such as data ware housing, OLAP and data mining. To obtain more objective result an expert-average group evaluation strategy was added to Fuzzy TOPSIS.

Benitzen et al. (2007) carried out a research on evaluating the service quality of three hotels of an important corporation in Gran Canaria island via survey. Fuzzy numbers based on fuzzy triangular numbers and fuzzy set theory was explained to overcome some linguistic problems. An overall service performance index was developed through TOPSIS for each pair hotel-date survey. This index can be helpful for hotel managers to understand their relative ranking position and provide a 
sufficient option for performance evaluation of hotel services involving subjective judgment of qualitative attributes. Zhu et al. (2012) judged credit quality. After establishing an indicator system of quality credit, TOPSIS was mentioned to evaluate the credit quality of eight air-conditioning enterprises in China market.

\subsection{Fuzzy}

Since fuzzy applications derived from fuzzy concept applied in articles frequently, fuzzy methods which were combined with another MCDM approach are described in other sections. This section focused on articles having fuzzy methods independently. Hu and Liao (2011) explained critical criteria of evaluating electronic service quality by employing fuzzy numbers to measure decision maker's subjective preferences. In addition, critical criteria for five domestic files in Taiwan were determined. Internet banks can enhance their service quality according to the result of this article.

Chou et al. (2011) made an effort to establish a fuzzy weighted SERVQUAL model for assessing the airline service quality. Taiwanese Airline was evaluated by this model. Lin (2010) used fuzzy sets to eliminate the subjective judgments in analyzing service quality. Büyüközkan, and Çifçi, (2012b) introduced a new group decision making approach that takes into consideration incomplete information of decision makers by means of fuzzy set theory. As a result, effectiveness of the evaluation in Quality Function Deployment (QFD) was enhanced. This procedure demonstrated its potential in collaborative software development process.

$\mathrm{Hu}$ and Liao (2009) measured decision maker's subjective preference for identifying critical criteria in assessing service quality of travel websites by fuzzy numbers. Dursan and Karsak (2013) expressed a fuzzy multi criteria group decision making approach using the Quality Function Deployment (QFD) concept for supplier selection process. The upper and lower bounds of the weights of supplier assessment criteria and rating of suppliers were computed by Fuzzy Weighted Average (FWA) method. The final ranking of suppliers was attained by a fuzzy number ranking method based on area measurement.

\subsection{Less frequent and hybrid procedures}

Some methods such as DEA, Goal Programming, Entropy and ELECTRE studied in articles rarely and special hybrid procedures with several MCDM methods are brought in this section. Khorramshahgol (1999) added the Delphi method to Shewhart's quality control technique in order to attain a methodology for group decision making in the presence of few objects. In empirical, Goal Programming was selected and tried to eliminate the subjectivity in problem formulation.

Teng and Tzeng (1994) illustrated a methodology for improving and controlling Air quality in a super city like Taipei city. At the onset, consensus elimination under key criteria was done for recognizing non-dominated strategies. After that, ELECTRE III was applied to prioritize non-dominated strategies under multiple criteria. Chan et al. (1999) rated the importance of customer needs in Quality Function Deployment (QFD) by fuzzy and Entropy approach.

Lee and Kim (2012) proposed a method for computing overall service quality and bench marking in measuring service quality with SERVQUAL by DEA. Chen and Chen (2012) constructed a network hierarchical feedback system (NHFS) based on the integration of Total Quality Management (TQM) and innovation to evaluate operation performance. This method including DEMATEL, Fuzzy ANP, Fuzzy AHP and GRA was applied for all types of universities in Taiwan. Huang et al. (2012) combined DEMATEL, ANP based framework and GRA to provide a new MCDM model for purging the service quality gap, satisfying customers and maximizing profits. Enhancing the service quality of a Taiwanese mobile telecommunication firm's application of cloud consumption as the billing system was done to validate the model. 


\section{Frequency of each MCDM methods}

It is interesting to learn more about the frequencies of various MCDM methods in quality improvement. Fig. 1 shows details of our survey in terms of percentage.

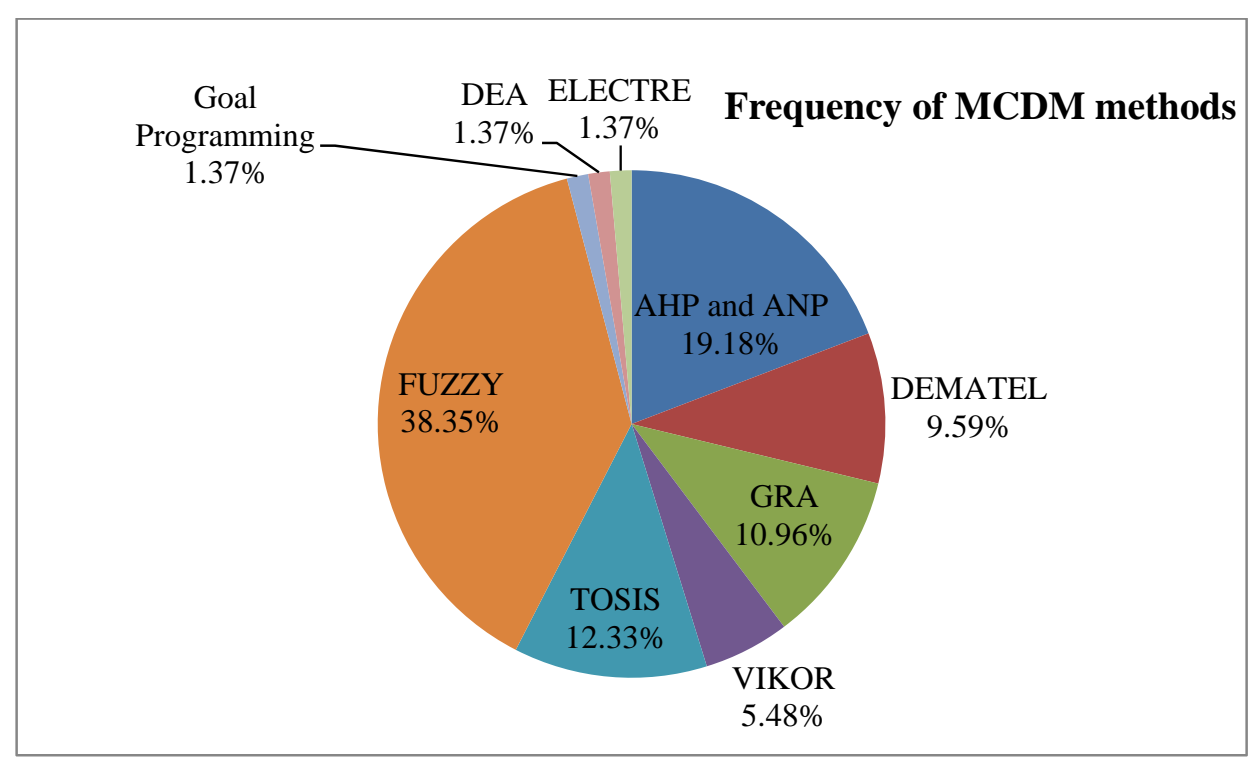

Fig. 1. Frequencies of MCDM methods

According to Fig. 1, Fuzzy was the most frequent method with 40\% usage among MCDM methods followed by AHP and ANP were about $20 \%$ of applied methods. TOPSIS also was widely used in articles. In contrast, DEA, Goal Programming and ELECTRE were not employed very often.

\section{Conclusion remarks}

This survey explained articles, which were concentrated on MCDM application in quality problems. There were 45 articles published between 1994 and 2013 investigated to demonstrate effectiveness of MCDM methods as means for dealing with such problems. Fuzzy, AHP and ANP were widely used in the procedures, while some methods such as DEA, Goal programming and ELECTRE were not found very often.

Future researches on this field can be conducted in several directions. One of the aspects which were not investigated deeply was applying MCDM methods in Statistical Quality Control Problems (SQC). Also concerning to the existing of various objects in most of the organizations and businesses, there is an opportunity for further researches on application of Multi Objective Decision Making in quality problems.

\section{Acknowledgment}

The authors would like to thank anonymous referees for constructive comments on earlier version of this work.

\section{References}

Ahire, S. L., \& Rana, D. S. (1995). Selection of TQM pilot projects using an MCDM approach. International Journal of Quality \& Reliability Management, 12(1), 61-81.

Benítez, J. M., Martín, J. C., \& Román, C. (2007). Using fuzzy number for measuring quality of service in the hotel industry. Tourism Management, 28(2), 544-555. 
Bhattacharya, A., Geraghty, J., \& Young, P. (2010). Supplier selection paradigm: An integrated hierarchical QFD methodology under multiple-criteria environment. Applied Soft Computing, 10(4), 1013-1027.

Bilsel, R. U., Büyüközkan, G., \& Ruan, D. (2006). A fuzzy preference-ranking model for a quality evaluation of hospital web sites. International Journal of Intelligent Systems, 21(11), 1181-1197.

Bueyuekoezkan, G., \& Ruan, D. (2007). Evaluating government websites based on a fuzzy multiple criteria decision-making approach. International Journal of Uncertainty, Fuzziness and Knowledge-Based Systems, 15(03), 321-343.

Büyüközkan, G., Çifçi, G., \& Güleryüz, S. (2011). Strategic analysis of healthcare service quality using fuzzy AHP methodology. Expert Systems with Applications, 38(8), 9407-9424.

Büyüközkan, G., \& Çifçi, G. (2012a). A combined fuzzy AHP and fuzzy TOPSIS based strategic analysis of electronic service quality in healthcare industry. Expert Systems with Applications, 39(3), 2341-2354.

Büyüközkan, G., \& Çifçi, G. (2012b). A new incomplete preference relation based approach to quality function deployment. Information Sciences, 206(5), 30-41.

Cebi, S. (2012). A quality evaluation model for the design quality of online shopping websites. Electronic Commerce Research and Applications.

Chan, L. K., Kao, H. P., \& Wu, M. L. (1999). Rating the importance of customer needs in quality function deployment by fuzzy and entropy methods. International Journal of Production Research, 37(11), 2499-2518.

Chang, C. W., Wu, C. R., \& Chen, H. C. (2008). Using expert technology to select unstable slicing machine to control wafer slicing quality via fuzzy AHP. Expert Systems with Applications, 34(3), 2210-2220.

Charnes, A., Cooper, W. W., \& Rhodes, E. (1978). Measuring the efficiency of decision making units. European Journal of the Operational Research, 2, 429-44.

Charnes, A., Cooper W. W., Lewin, A., \& Seiford, L. M. (1994). Data envelopment analysis: theory, methodology and applications. Massachusetts: Kluwer Academic Publishers.

Che, Z. H., Wang, H. S., \& Chuang, Ch-L. (2010). A fuzzy AHP and DEA approach for making bank loan decisions for small and medium enterprises in Taiwan. Expert Systems with Applications, 37(10), 7189-7199.

Chen, J. K., \& Chen, I. (2012). A network hierarchical feedback system for Taiwanese universities based on the integration of total quality management and innovation. Applied Soft Computing.

Chou, C. C., Liu, L. J., Huang, S. F., Yih, J. M., \& Han, T. C. (2011). An evaluation of airline service quality using the fuzzy weighted SERVQUAL method. Applied Soft Computing, 11(2), 21172128.

Chou, W. C., \& Cheng, Y. P. (2012). A hybrid fuzzy MCDM approach for evaluating website quality of professional accounting firms. Expert Systems with Applications, 39(3), 2783-2793.

Deng, J. L. (1982).Control problems of grey systems. Systems \& Control Letters, 5, 288-294.

Deng, J. L. (1984). The theory and methods of socio-economic grey systems. Social science in China, 6, 29-46.

Dursun, M., \& Ertugrul Karsak, E. (2012). A QFD-Based Fuzzy MCDM Approach for Supplier Selection. Applied Mathematical Modelling.

Fatchurrohman, N., Sulaiman, S., Sapuan, S. M., Ariffin, M. K. A., \& Baharudin, B. T. (2012). A new concurrent engineering-multi criteria decision making technique for conceptual design selection. Applied Mechanics and Materials, 225, 293-298.

Fontela. E., \& Gabus. A. (1976). The DEMATEL observer, DEMATEL 1976 Report, Switzerland, Geneva: Battelle Geneva Research Center.

Gabus, A., \& Fontela, E. (1973). Perceptions of the World problematic: Communication procedure, communicating with those bearing collective responsibility, 1.Switzerland Geneva: Battelle Geneva Research Centre. 
Hessami, H. Z., Golsefid-Alavi, M., Shekaf, S. M., \& Mavi, R. K. (2012). Evaluation of success factors of ISO 14001-Based EMS implementation and ranking the cement industry uUsing the TOPSIS method. Journal of Applied Environmental Biological Science, 2(10), 523-530.

Hsieh, L. F., Lin, L. H., \& Lin, Y. Y. (2008). A service quality measurement architecture for hot spring hotels in Taiwan. Tourism Management, 29(3), 429-438.

Hu, Y. C. (2009). Fuzzy multiple-criteria decision making in the determination of critical criteria for assessing service quality of travel websites. Expert Systems with Applications, 36(3), 6439-6445.

Hu, Y. C., \& Liao, P. C. (2011). Finding critical criteria of evaluating electronic service quality of Internet banking using fuzzy multiple-criteria decision making. Applied Soft Computing, 11(4), 3764-3770.

Hwang, C. L., \& Yoon, K. P. (1981). Multiple attribute decision making: Methods and applications. New York: Springer-Verlag.

Huang, C. Y., Hsu, P. C., \& Tzeng, G. H. (2012). Evaluating cloud computing based telecommunications service quality enhancement by using a new hybrid MCDM model. Intelligent Decision Technologies, 519-536.

Khorramshahgol, R. (1999). Augmenting Shewhart quality control and Delphi method for multiperson, multi-objective decision-making. Telematics and Informatics, 16(1), 1-9.

Kudou, A., Chen, Y., \& Yeh, L. (2012). Comment on "Using a modified grey relation method for improving airline service quality”. Tourism Management, 33(3), 717-718.

Kuo, M. S. (2011a). A novel interval-valued fuzzy MCDM method for improving airlines' service quality in Chinese cross-strait airlines. Transportation Research Part E: Logistics and Transportation Review, 47(6), 1177-1193.

Kuo, M. S., \& Liang, G. S. (2011b). Combining VIKOR with GRA techniques to evaluate service quality of airports under fuzzy environment. Expert Systems with Applications, 38(3), 1304-1312.

Lee, H., \& Kim, C. (2012). A DEA-SERVQUAL approach to measurement and benchmarking of service quality. Procedia-Social and Behavioral Sciences, 40, 756-762.

Lin, T. T., Lee, Ch-Ch., \& Chiu, T-F. (2009). Application of DEA in analyzing a bank's operating performance. Expert Systems with Applications, 36(5), 8883-8891.

Lin, H. T. (2010). Fuzzy application in service quality analysis: an empirical study. Expert Systems with Applications, 37(1), 517-526.

Liou, J. J., \& Tzeng, G. H. (2007). A non-additive model for evaluating airline service quality. Journal of Air Transport Management, 13(3), 131-138.

Liou, J. J., Hsu, C. C., Yeh, W. C., \& Lin, R. H. (2011a). Using a modified grey relation method for improving airline service quality. Tourism Management, 32(6), 1381-1388.

Liou, J. J., Tsai, C. Y., Lin, R. H., \& Tzeng, G. H. (2011b). A modified VIKOR multiple-criteria decision method for improving domestic airlines service quality. Journal of Air Transport Management, 17(2), 57-61.

Majumdar, A., Sarkar, B., \& Majumdar, P. K. (2005). Determination of quality value of cotton fibre using hybrid AHP-TOPSIS method of multi-criteria decision-making. Journal of the Textile Institute, 96(5), 303-309.

Oh, G. O., Kim, D. Y., Kim, S. I., \& Rhew, S. Y. (2006, November). A quality evaluation technique of RFID middleware in ubiquitous computing. In Hybrid Information Technology, 2006. ICHIT'06. International Conference on (Vol. 2, pp. 730-735). IEEE.

Opricovic, S., \& Tzeng, G. H. (2004). Compromise solution by MCDM methods: A comparative analysis of VIKOR and TOPSIS. European Journal of Operational Research, 156(2), 445-455.

Raut, R. D., Bhasin, H. V., \& Kamble, S. S. (2011). Multi-criteria decision-making for automobile purchase using an integrated analytical quality fuzzy (AQF) technique. International Journal of Services and Operations Management, 10(2), 136-167.

Roy, B. (1991). The outranking approach and the foundations of ELECTRE methods. Theory and Decision, 31, 49-73.

Saremi, M., Mousavi, S. F., \& Sanayei, A. (2009). TQM consultant selection in SMEs with TOPSIS under fuzzy environment. Expert Systems with Applications, 36(2), 2742-2749. 
Saaty, T.L. (1980). The Analytic Hierarchy Process. Boston: McGraw-Hill, Inc.

Saaty, T.L. (2001). Decision Making with Dependence and Feedback: the Analytic Network Process (2nd ed.). Pittsburgh: RWS Publications.

Shahin, A., \& Poormostafa, M. (2011). Facility layout simulation and optimization: An integration of advanced quality and decision making tools and techniques. Modern Applied Science, 5(4), p95.

Teng, J. Y., \& Tzeng, G. H. (1994). Multicriteria evaluation for strategies of improving and controlling air quality in the super city: a case study of Taipei city. Journal of Environmental Management, 40(3), 213-229.

Thoraneenitiyan, N., \& Avkiran, N. K. (2009). Measuring the impact of restructuring and countryspecific factors on the efficiency of post-crisis East Asian banking systems: Integrating DEA with SFA. Socio-Economic Planning Sciences, 43(4), 240-252.

Tsaur, S. H., Chang, T. Y., \& Yen, C. H. (2002). The evaluation of airline service quality by fuzzy MCDM. Tourism Management, 23(2), 107-115.

Tseng, M. L. (2009a). Application of ANP and DEMATEL to evaluate the decision-making of municipal solid waste management in Metro Manila. Environmental monitoring and assessment, 156(1), 181-197.

Tseng, M. L. (2009b). A causal and effect decision making model of service quality expectation using grey-fuzzy DEMATEL approach. Expert systems with applications, 36(4), 7738-7748.

Tseng, M. L., Chen, Y. H., \& Geng, P. Y. (2012). Integrated model of hot spring service quality perceptions under uncertainty. Applied Soft Computing.

Wang, R., Lin, Y. H., \& Tseng, M. L. (2011). Evaluation of customer perceptions on airline service quality in uncertainty. Procedia-Social and Behavioral Sciences, 25, 419-437.

Wang, C. H., \& Chen, J. N. (2012). Using quality function deployment for collaborative product design and optimal selection of module mix. Computers \& Industrial Engineering.

Zadeh, L. A. (1965). Fuzzy sets. Information and control, 8(3), 338-353.

Zhu, Y. (2008). Group assessment of web source/information quality based on WebQM and fuzzy logic. Rough Sets and Knowledge Technology, 660-667.

Zhu, X., Wang, F., Liang, C., Li, J., \& Sun, X. (2012). Quality Credit Evaluation based on TOPSIS: Evidence from Air-conditioning Market in China. Procedia Computer Science, 9, 1256-1262. 